\title{
Pengatur Kecepatan Prototipe Mesin Solenoid 4 Induktor Menggunakan Metode Kontrol Frekuensi
}

\author{
Yusuf Nurul Hilal $^{1)}$, Trias Andromeda ${ }^{2)}$, dan Susatyo Handoko ${ }^{3)}$ \\ 1) Jurusan Teknik Elektro, Fakultas Teknik, Universitas Semarang \\ ${ }^{2,3)}$ Departemen Teknik Elektro Fakultas Teknik, Universitas Diponegoro \\ 1) Jl. Soekarno Hatta, Tlogosari Kulon, Pedurungan, Semarang, Indonesia 59160 \\ ${ }^{2,3)} \mathrm{Jl}$. Prof. Soedarto, SH, Kampus UNDIP Tembalang, Semarang, Indonesia 50275 \\ e-mail:yhila12@gmail.com ${ }^{1)}$
}

\begin{abstract}
The development of electric vehicles is in rapid progress, especially in terms of the main engine drive. The use of solenoid can be applied as an alternative driving electric vehicles instead of a dc motor as the main driver. In this paper, the prototype solenoid machine is applied by using 4 inductors controlled by an Arduino microcontroller and the solenoid driver based on application of Mosfet L298N. The prototype runs successfully. Based on the experimental results, the greater the frequency value applies to the driver, the faster the solenoid moves. The acceleration occures due to the electromagnetic field which is getting stronger and the field is proportional to the frequency value, so the solenoid movement is faster.
\end{abstract}

Keywords: solenoid, frequency, electric vehicle

ABSTRAK
Perkembangan kendaraan listrik mengalami kemajuan pesat, terutama dalam hal penggerak mesin utama. Penggunaan solenoid bisa diterapkan dalam mencari alternatif penggerak kendaraan listrik, selain menggunakan motor dc sebagai penggerak utamanya. Percobaan prototipe mesin solenoid menggunakan 4 induktor yang dikontrol menggunakan mikrokontroler arduino dan driver solenoid menggunakan Mosfet L298N telah berhasil dilakukan. Berdasarkan percobaan, dapat disimpulkan bahwa semakin besar nilai frekuensi yang dikeluarkan, semakin cepat solenoid bergerak. Hal tersebut dikarenakan medan elektromagnetik yang semakin kuat dan sebanding dengan nilai frekuensi yang semakin besar, sehingga gerakan solenoid juga semakin cepat.

Kata kunci: solenoid, frekuensi, kendaraan listrik

\section{Pendahuluan}

$\mathrm{P}$ erkembangan teknologi kendaraan listrik semakin berkembang pesat di berbagai negara beberapa tahun terakhir, dengan tujuan dapat mengurangi polusi udara dari hasil pembakaran bahan bakar fosil [1] dan ikut serta dalam mengurangi efek rumah kaca [2]. Penerapannya sudah dapat dijumpai diberbagai produk kendaraan listrik, diantaranya sepeda listrik, motor listrik dan mobil listrik. Penerapan motor listrik dalam industri kendaraan listrik masih sangat besar, dimana motor listrik bekerja sesuai prinsip induksi elektromagnetik, yaitu mengubah energi listrik menjadi energi kinetik [3].

\section{Solenoid}

\section{TEORI}

Beberapa dekade terakhir sedang banyak dilakukan penelitian tentang penggunaan mesin solenoid dalam menggantikan motor listrik, karena penggunannya yang juga ramah lingkungan dan tidak rumit dalam susunan mesin. Penggunaan solenoid juga banyak digunakan pada sistem pneumatik dan hidrolik [4][5][6]. Cara kerja solenoid adalah saat arus listrik mengalir ke induktor, kemudian menimbulkan medan magnet yang berfungsi sebagai elektromagnet, dimana akan terjadi gaya tarik pada benda yang bersifat magnetik. Sebuah piston akan dipasang di dalam solenoid yang terhubung dengan penggerak, kemudian terjadi gaya dorong yang disebabkan energi elektromagnetik oleh induktor yang dialiri arus listrik [7][8]. Hal ini sesuai dengan prinsip kerja medan magnet.

Metode kontrol solenoid yang pernah dilakukan sebelumnya adalah dengan menggunakan switching transistor, dimana komponen ini mampu bekerja sebagai switch dengan kecepatan yang tinggi [3]. Pengontrol elektronik yang digunakan harus responsif dan stabil karena gerakan solenoid akan sangat cepat. Pada metode ini gerakan solenoid tergantung pada kondisi output dari switching transistor yang dikendalikan oleh mikrokontroler, kemudian switching akan berstatus I/O dalam mengalirkan arus listrik ke induktor.

Selain metode switching transistor, ada juga metode lain yang digunakan dalam mengendalikan solenoid. Metode ini menggunakan variasi tegangan dalam mengendalikan kecepatan dan torsi solenoid [9]. Dalam penerapan metode variasi tegangan digunakan sumber tegangan DC, karena setelah dilakukan uji coba, sumber tegangan DC lebih aman dibanding dengan sumber tegangan AC, yang dapat menyebabkan kumparan lebih cepat panas. 
Mesin solenoid mempunyai persamaan dengan mesin konvensional, yaitu sama-sama memiliki tabung silinder, piston, batang penghubung dan poros engkol. Dilihat dari desain mesin dan perspektif operasional, mesin solenoid memiliki beberapa keunggulan dibandingkan dengan mesin kendaraan listrik yang sudah ada [10]. Tetapi perbedaan yang jelas terlihat antara mesin solenoid dan mesin konvensional adalah bahan bakar yang digunakan. Salah satu keuntungan dari mesin solenoid adalah bebas polusi udara, serta mudah dalam merancang struktur mesin. Karena mesin solenoid dalam kendaraan listrik tidak memiliki ruang pembakaran, katup, sistem pendingin air, pompa bahan bakar, saluran bahan bakar, filter udara dan tidak menggunakan bahan bakar cair[11]. Sehingga penggunaan mesin solenoid menjadi ramah lingkungan.

\section{Metode Penelitian}

\section{A. Metode Kontrol}

Berdasarkan uraian beberapa metode diatas, maka penelitian kali ini akan mencoba penggantian komponen utama dalam kendaraan listrik yaitu motor DC akan digantikan dengan solenoid. Dibuat prototipe mesin solenoid 4 induktor bersumber tegangan DC, dengan kecepatan gerak yang dikontrol frekuensi, yang dibangkitkan dari mikrokontroler.

Sebuah potensiometer terhubung dengan mikrokontroler yang berfungsi sebagai pengubah nilai keluaran frekuensi dari mikrokontroler. Pada rangkaian ini output dari mikrokontroler akan terhubung ke driver solenoid yang berfungsi sebagai switch arus listrik menuju solenoid, kemudian terjadi gerakan mendorong. Pengamatan akan dilakukan dengan cara mengukur nilai RPM dan nilai frekuensi menggunakan tachometer dan osiloskop.

Mengacu pada referensi yang sudah ada, gerakan prototipe mesin solenoid akan dikelompokkan menjadi dua bagian, dan bekerja secara bergantian [12]. Solenoid bekerja saat posisi pertama piston pada solenoid 1 dan 2 akan bergerak menekan kebawah karena mengalami gaya tarik magnet, sedangkan posisi piston pada solenoid 3 dan 4 akan mengarah ke atas, karena terdorong. Setelah itu akan bergantian posisi piston solenoid 3 dan 4 menekan kebawah karena gaya tarik magnet, sedangkan posisi piston solenoid 1 dan 2 mengarah ke atas. Kejadian tersebut akan terjadi berulang-ulang selama mesin bekerja.

\section{B. Alat dan bahan}

Dalam melaksanakan penelitian, diperlukan alat serta bahan pendukung berupa hardware dan software. Berikut ini adalah alat dan bahan yang diperlukan:
a. Arduino UNO
b. Driver Solenoid L298N H-Bridge
c. Solenoid (Induktor)
d. I2C (Integrated Circuit) dan LCD (Liquid Crystal Display)
e. Potensiometer Rotary
f. Power Supply
g. Software Arduino IDE 1.8.10

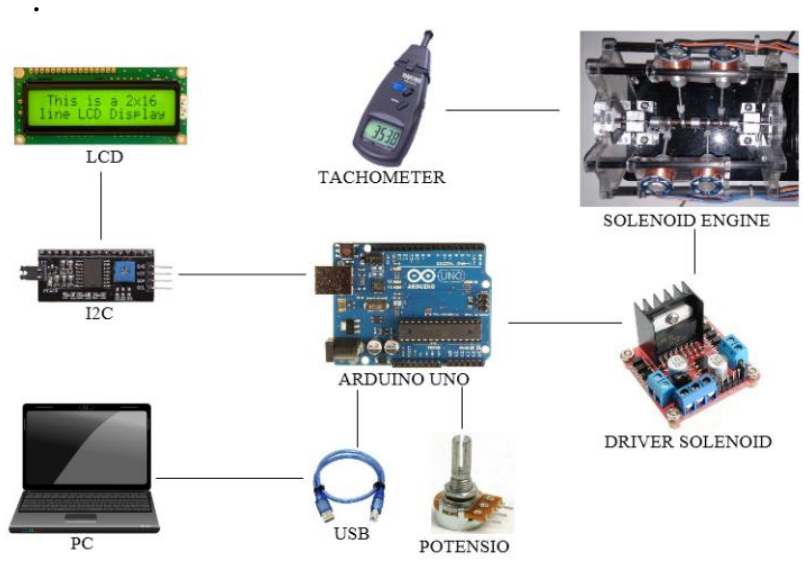

Gambar 1. Rangkaian Penelitian

Gambar 1 menunjukkan sebuah rangkaian keseluruhan dan peralatan yang digunakan dalam penelitian ini. Solenoid yang digunakan pada prototipe mesin solenoid mempunyai spesifikasi sebagai berikut:

a. Panjang induktor (L): $1 \mathrm{~cm}$

b. Jari-jari inti induktor (a) $: 1 \mathrm{~cm}$

c. Diameter kawat induktor (d) $: 0.02 \mathrm{~cm}$

d. Jumlah lilitan per lapis (N) : 50

e. Jumlah lapisan (n) : 10 lapis

f. Tebal lapisan (D) $\quad: 0.5 \mathrm{~cm}$

\section{Rangkaian Keseluruhan}

Alat yang diuji coba dalam penelitian ini terdiri dari prototipe mesin solenoid dan rangkaian pengendali frekuensi menggunakan mikrokontroler arduino uno. Serta driver pengendali solenoid menggunakan mosfet L298N. Gambar 2 menggambar rangkaian alat keseluruhan dalam penelitian ini.

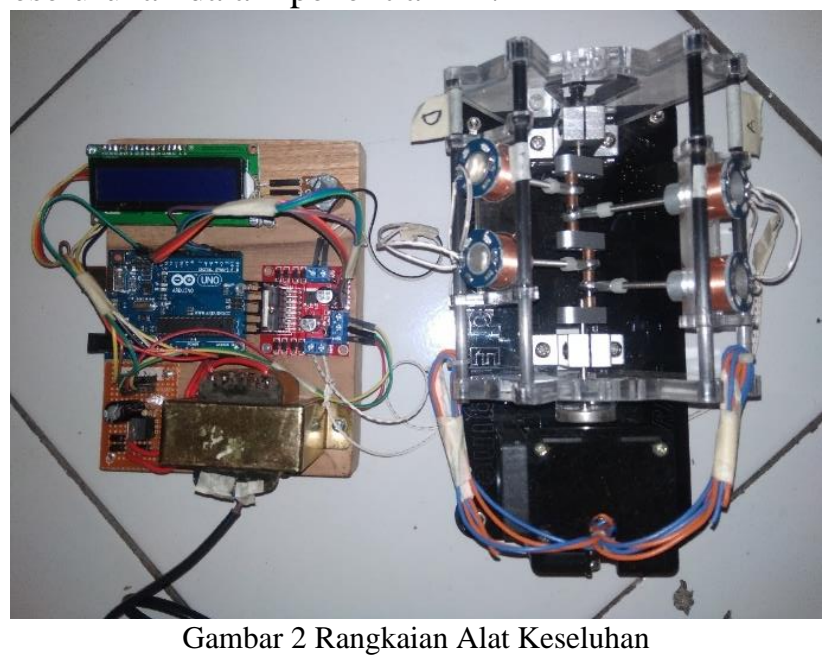

\section{Pemrograman Mikrokontroler}

Pemrograman mikrokontroler arduino uno dalam penilitian ini dilakukan menggunakan software arduino IDE 1.8.10. Bertujuan agar output dari mikrokontroler dapat mengeluarkan frekuensi yang berbeda beda. 


\section{E. Simulasi}

Simulasi percobaan dilakukan dengan mengukur hasil kecepatan pada prototipe mesin solenoid menggunakan tachometer. Dapat dilihat pada Gambar 3.

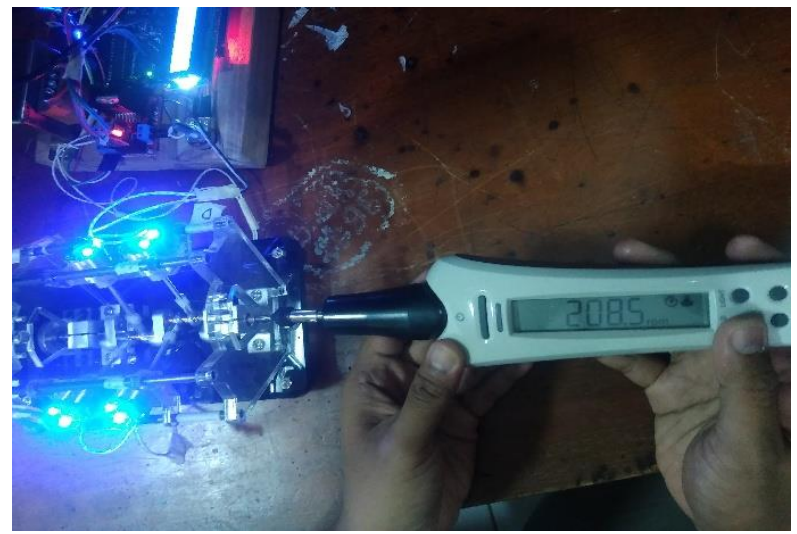

Gambar 3. Pengukuran Kecepatan

Begitu juga dengan pengukuran nilai frekuensi yang dilakukan menggunakan osiloskop, dapat dilihat pada Gambar 4

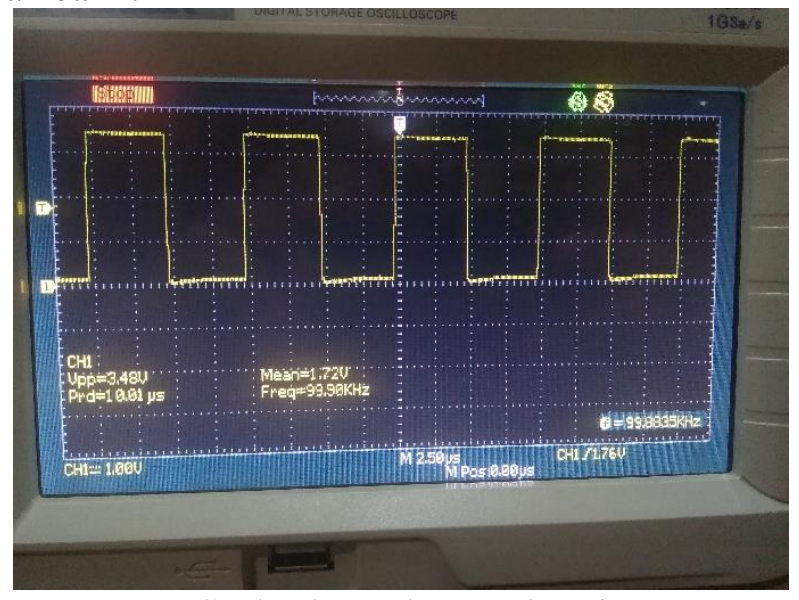

Gambar 4 Pengukuran Frekuensi

\section{HASIL DAN PEMBAHASAN}

Hasil pengukuran yang telah dilakukan disajikan pada Tabel 1. Dapat dilihat mengenai pengaruh nilai frekuensi terhadap kecepatan yang dihasilkan oleh prototipe mesin solenoid. jadi semakin besar nilai frekuensi yang dihasilkan, semakin besar juga nilai RPM yang didapatkan.

\begin{tabular}{|c|c|c|c|c|}
\multicolumn{5}{|c}{ Tabel 1. Hasil Pengukuran } \\
\hline \multirow{2}{*}{ No. } & \multicolumn{2}{|c|}{$\begin{array}{c}\text { Solenoid } \\
\text { (VDC) }\end{array}$} & $\begin{array}{c}\text { RPM Sole- } \\
\text { noid Engine }\end{array}$ & $\begin{array}{c}\text { Frequency } \\
\text { (KHz) }\end{array}$ \\
\cline { 2 - 3 } & $\mathbf{A}$ & $\mathbf{B}$ & & \\
\hline $\mathbf{1 .}$ & 1,2 & 12 & 0 & 52,58 \\
\hline $\mathbf{2 .}$ & 1,4 & 1,4 & 141,3 & 71,38 \\
\hline $\mathbf{3 .}$ & 1,8 & 1,8 & 208,5 & 99,90 \\
\hline $\mathbf{4 .}$ & 2,4 & 2,4 & 230,1 & 166,6 \\
\hline $\mathbf{5 .}$ & 3,4 & 3,4 & 461,2 & 332,8 \\
\hline
\end{tabular}

Untuk lebih jelasnya pengaruh frekuensi terhadap kecepatan gerak solenoid dapat dilihat pada sebuah kurva yang di tunjukkan pada Gambar 5.

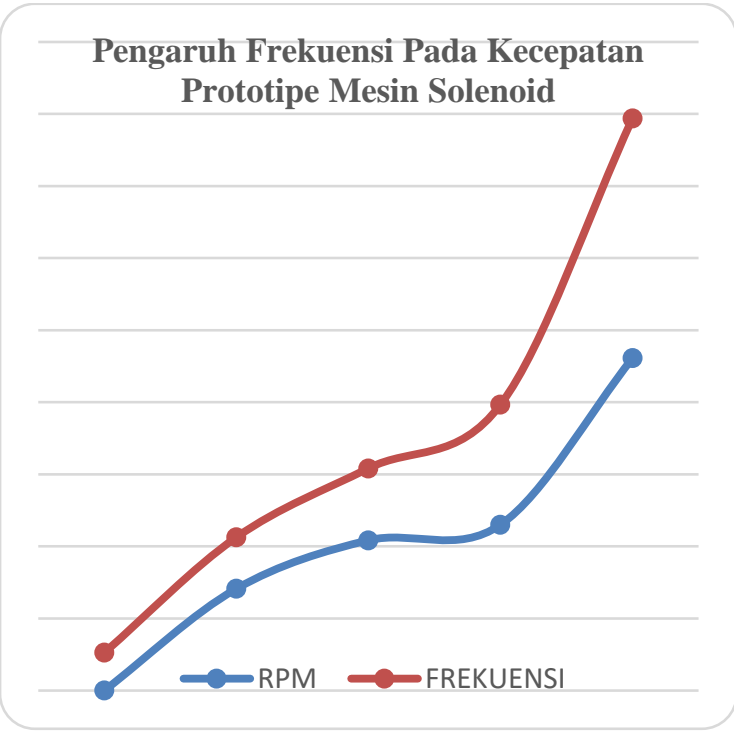

Gambar 5. Pengaruh Frekuensi Pada Kecepatan

Begitu pula dengan tegangan yang dihasilkan, semakin besar nilai duty cycle semakin besar juga nilai tegangan yang keluar menuju solenoid, nilainya dapat dilihat pada Tabel 1. Tetapi dalam uji coba yang dilakukan, nilai frekuensi belum bisa berubah. Sehingga belum terlihat pengaruh perubahan nilai frekuensi terhadap cara kerja solenoid.

\section{KESIMPULAN}

Setelah dilakukan percobaan dapat disimpulkan bahwa pengendalian prototipe mesin solenoid 4 induktor dengan metode kontrol nilai frekuensi berhasil dilakukan. Hal tersebut dibuktikan dengan semakin bertambahnya nilai frekuensi yang dihasilkan, semakin besar juga nilai kecepatan yang diperoleh. Driver yang digunakan dalam mengendalikan solenoid adalah Mosfet L298N H-Bridge. Kecepatan gerak prototipe mesin solenoid dipengaruhi semakin kuat gaya medan magnet yang terjadi pada induktor seiring bertambahnya nilai frekuensi, sehingga torsi dorongan yang terjadi juga semakin kuat.

\section{DAFTAR PUSTAKa}

[1] J. Du, X. Meng, J. Li, X. Wu, Z. Song, and M. Ouyang, "Insights into the Characteristics of Technologies and Industrialization for Plug-In Electric Cars in China," ENERGY, pp. 1-32, 2018.

[2] N. Ding, K. Prasad, and T. T. Lie, "The electric vehicle : a review," vol. 9, no. 1, pp. 49-66, 2017.

[3] S. Zainal et al., "Evaluating the Potential of Solenoid Motion System for Electric Vehicle - Challenging the Conventional Usage of Electric Motor," no. PECon 08, pp. 726-730, 2008.

[4] H. Kang, J. Park, J. Cho, J. Kim, and J. Oh, "A New Method for Maintaining Constant Dither Amplitude 
in Low Frequency PWM," AECE, vol. 17, no. 1, pp. 89-94, 2017.

[5] Ž. Šitum, T. Žili, and M. Essert, "High Speed Solenoid Valves in Pneumatic Servo Applications," IEEE, 2007.

[6] A. Rahman, M. Rahman, and H. Karim, "The Theory of the Development of an Electromagnetic Engine for Automotive Use," Symbiosis, 2017.

[7] M. M. Akhtar, S. K. Tripathy, E. P. Kumar, S. Biswal, S. Kumar, and H. S. Dash, "Solenoid Engine," IJSDR, vol. 2, no. 4, pp. 297-301, 2017.

[8] A. Mannur, R. Patil, S. Padalkar, and K. Prem, "Electromagnetic Engine with an Objective of Lowering Pollution," IARJSET, vol. 4, no. 6, pp. 3235, 2017.

[9] S. Zainal, A. Syed, and K. Bahrin, "Design and Development of a New Electromagnetic Prime Mover Using Solenoid Technology - Solenoid Powered Engine Mathematical Derivations (Inductance Variation)," IEEE, pp. 277-281, 2014.

[10] S. Zainal, A. Syed, and K. Bahrin, "Design and Development of a New Electromagnetic Prime Mover Using Solenoid Technology - Solenoid Powered Engine Model Simulation (Torque Vs. Speed Characteristic) Syed," IEEE, pp. 255-259, 2014.

[11] A. K. A. N. Y. Vijay Kumar, Anurag, Abhishek Rocky, Ashutosh Kumar, "ORIGINAL RESEARCH PAPAER - SOLENOID ENGINE," PARIPEX INDIAN J. Res., vol. 6, no. 7, pp. 33-35, 2017.

[12] J. Rithula, J. Jeyashruthi, and Y. Anandhi, "Electric Vehicle with Zero-fuel Electromagnetic Automobile Engine," Int. J. Eng. Res. Technol., vol. 6, no. 4, pp. 483-486, 2013. 